Copyright $(0) 2018$ by the author(s). Published here under license by the Resilience Alliance.

McCarter, J., E. J. Sterling, S. D. Jupiter, G. D. Cullman, S. Albert, M. Basi, E. Betley, D. Boseto, E. S. Bulehite, R. Harron, P. S. Holland, N. Horning, A. Hughes, N. Jino, C. Malone, S. Mauli, B. Pae, R. Papae, F. Rence, O. Revo, E. Taqala, M. Taqu, H. Woltz, and C. E. Filardi. 2018. Biocultural approaches to developing well-being indicators in Solomon Islands. Ecology and Society 23 (1):32. https://doi.org/10.5751/ES-09867-230132

Insight, part of a Special Feature on A brave new world: integrating human well-being in conservation

\title{
Biocultural approaches to developing well-being indicators in Solomon Islands
}

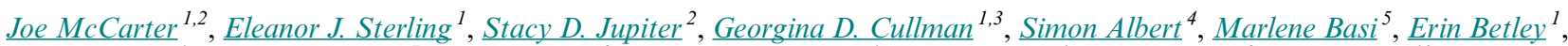

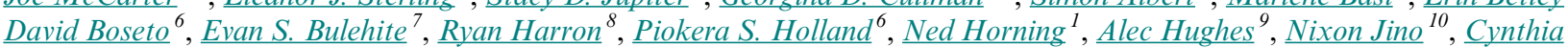 \\ Malone $^{1}, \underline{\text { Senoveva Mauli }}^{11}, \underline{\text { Bernadette Pae }}^{5}$, Remmy Papae $^{12}{ }^{\text {Ferish Rence }^{7}}$, Oke Revo $^{10}{ }^{10}$ Ezekiel Taqala $^{5}$, Miri Taqu $^{13}, \underline{\text { Hara }}$ \\ Woltz $^{1}$ and Christopher E. Filardi ${ }^{14}$
}

\begin{abstract}
To meet local and global aspirations toward sustainable resource management, we must first understand what success looks like. At global levels, well-being can be narrowly defined, which may clash with local values and cause adverse impacts. Melanesia is home to a complex mosaic of resource management systems, and finding locally appropriate indicators of success poses particular challenges. We propose that biocultural approaches can assist in developing grounded and appropriate well-being indicators. Biocultural approaches frame issues from the perspectives of place-based communities and work with resource users to develop desired outcomes. In doing so, biocultural approaches recognize links between people and the environment and seek to understand feedbacks between social and ecological components. Biocultural approaches may help to improve the fit between local aspirations and national or international actions and can also cocreate knowledge that draws on local knowledge and practice as well as western science. Here, we report on one such approach in Western Province, Solomon Islands, where rural communities are weighing a variety of trade-offs around the use of natural resources. The work encompasses four locations and seeks to define local needs and priorities, develop appropriate local indicators of success, assess indicator baselines, and catalyze appropriate action. Implementation challenges have included scaffolding between local and national levels and the diversity of the four locations. These have, however, been offset by the engaged nature of indicator creation, which assists communities in planning toward action around local definitions of wellbeing.
\end{abstract}

Key Words: biocultural; indicators; monitoring and evaluation; resource management; Solomon Islands; Western Province

\section{INTRODUCTION}

Conservation and development programs increasingly seek improvements in human and ecological well-being. However, success in these terms hinges on an accurate understanding of place-based cultural, economic, and ecological values (Caillon et al. 2017, Sterling et al. 2017a). As such, we need to link human and ecological well-being explicitly, consider a wide range of variables and the feedbacks between them, and make a systematic attempt to balance specificity and scalability in different forms of local and global knowledge (Biedenweg et al. 2017, Sterling et al. 2017a). This is no easy task but is likely to be the only means of achieving just and equitable outcomes over the medium to long term.

Social-ecological systems theorists have defined human wellbeing as "...a state of being with others and the natural environment that arises where human needs are met, where individuals and groups can act meaningfully to pursue their goals, and where they are satisfied with their way of life" (Armitage et al. 2012). Universal and generic definitions of ecological well-being do not exist because it must be defined within a specific cultural context (Caillon et al. 2017). Similarly, definitions of human well-being are strengthened by a nuanced understanding of context (e.g., Taylor 2008).
While current global development and conservation initiatives (e.g., Convention on Biological Diversity, Sustainable Development Goals) have supported progress on many fronts, many of their measures of success are based on western worldviews of sustainability and well-being (Sterling et al. 2017a, $b$ ). For example, the amount of land in formal protected areas remains a common metric of ecological well-being despite the fact that it may undervalue the contribution of stewardship from local and indigenous peoples (Büscher et al. 2017). Similarly, a requirement in international guidelines for biodiversity conservation to be a primary objective of resource management planning (e.g., Dudley 2008) may run counter to the values and norms that govern resource use in the Pacific (e.g., Jupiter 2017). This mismatch between local realities and global agendas can have negative impacts, from the misdirection of resources (e.g., Bunce et al. 2010) to the disenfranchisement of place-based communities (Brockington et al. 2006).

In response, scholars and practitioners have worked to contextualize indicators of social and ecological well-being using a variety of approaches (Fraser et al. 2006). Examples of these approaches include using social-ecological systems theory to monitor marine resource management (Hughes et al. 2012); examining linked social-ecological indicators in agro-ecosystems

${ }^{1}$ Center for Biodiversity and Conservation, American Museum of Natural History, ${ }^{2}$ Melanesia Program, Wildlife Conservation Society, Fiji, ${ }^{3}$ Forestry, Horticulture, and Natural Resources, New York City Department of Parks \& Recreation, ${ }^{4}$ School of Civil Engineering, University of Queensland, ${ }^{5}$ West Parara, Parara Island, Western Province, Solomon Islands, ${ }^{6}$ Ecological Solutions Solomon Islands, Gizo, Solomon Islands, ${ }^{7}$ Vavanga, Kolombangara Island, Western Province, Solomon Islands, ${ }^{8}$ Biche, Gatokae Island, Western Province, Solomon Islands, ${ }^{9}$ Coastal Marine Management, Munda, Solomon Islands, ${ }^{10}$ Zaira, Vangunu Island, Western Province, Solomon Islands, ${ }^{11}$ Solomon Islands Community Conservation Partnership, Honiara, Solomon Islands, ${ }^{12}$ Solomon Islands Community Conservation Partnership, Batuna, Solomon Islands,

${ }^{13}$ Munda, New Georgia, Western Province, Solomon Islands, ${ }^{14}$ Nia Tero, Seattle, Washington, USA 
(van Oudenhoven et al. 2011); developing locally framed assessments of basic needs (Wilkie et al. 2015); cocreating indicators of well-being through participatory engagement of various stakeholder groups (Biedenweg et al. 2017); and, in Vanuatu, developing indicators that align with local conceptions of well-being (Tanguay 2015). At an international scale, some efforts have recognized that there are feedbacks between social and ecological processes and that human well-being is linked to the ecological state (e.g., Bergamini et al. 2013, Naeem et al. 2016).

However, there is limited literature discussing the process for creating indicators that reflect place-based social and cultural contexts (we use the term "place-based," in preference to "local" or "traditional," to reflect groups who share a history, rely on natural resources, make decisions, and have cultural and social systems within a common geography). These social and cultural contexts are critical to developing nuanced indicators of wellbeing, which themselves may fundamentally shape social and environmental outcomes (Sterling et al. 2017a). Here, we describe our efforts to address this gap in four locations in Solomon Islands and reflect on some of the opportunities and challenges of the "biocultural" approach we have taken in this work.

\section{BIOCULTURAL APPROACHES TO INDICATOR DEVELOPMENT IN SOLOMON ISLANDS}

We report on work in Western Province, Solomon Islands (referred to throughout as "the program"). The program began in 2014 and is ongoing at the time of writing. The program's aim is to work alongside communities to identify locally framed indicators of well-being and, in doing so, to support planning at the four sites. Success, in this context, was defined at each of the sites and was translated to Solomon Island Pijin as "achieving the good life."

We are a team of place-based researchers, scientists (with specialties spanning from ecology to social science) and conservation practitioners, all of whom are coauthors of this paper. Of the 25 coauthors, 14 are trained to a postgraduate level in an academic institution, 15 are from Solomon Islands, and 10 live at the sites. All team members involved in sustained on-theground research speak Solomon Islands Pijin, and the place-based research team is fluent in at least one of the four vernacular languages spoken at the sites.

\section{Conceptual approach}

We use the term "biocultural" here to recognize the inextricable linkages between biophysical and cultural realms. The term has a long history of use within subdisciplines of anthropology (see Maffi 2005). Recently, it has been used to describe approaches to conservation and development that explicitly recognize the rights of all parties and that seek to promote both biological and cultural diversity (e.g., Gavin et al. 2015, Sterling et al. 2017a).

We posit that biocultural approaches provide an effective way to develop nuanced and appropriate measures of well-being. We characterize biocultural approaches to indicator development as those that build on place-based cultural perspectives and recognize the links between ecological and social realms. Such approaches have the potential to strengthen the input of local voices in provincial, national, and regional forums; guide respectful engagement by nongovernmental organizations
(NGOs) and external researchers, and facilitate the application of multiple evidence based approaches (see Tengö et al. 2014). Moreover, they may be better suited to capturing place-based, relational, and subjective understandings of well-being (Caillon et al. 2017, Sterling et al. 2017a).

Biocultural approaches to well-being indicator development should include at least three major characteristics (Sterling et al. 2017a). First, they should be consonant with local ways of knowing, and so should begin with an understanding of placebased institutions, resources, and social groupings. Second, biocultural approaches should explicitly address interactions and feedbacks between the social and ecological components of the system from which well-being is derived as an emergent property. Third, biocultural approaches to indicator development should intend to assist local action. This is in contrast to some externally driven approaches that have little relevance to local management needs (e.g., Escobar 2014). Where external groups are involved, biocultural approaches should also seek to maintain continual engagement between groups over the life of the project and may result in the cocreation of knowledge (Reid et al. 2016).

Biocultural approaches build on and are conceptually linked to other approaches. Social-ecological systems (SESs) frameworks have proven to be effective to develop an understanding of feedbacks and linkages between different components of social and ecological systems (e.g., Brondizio et al. 2009). Similarly, participatory approaches to indicator development have made important progress in validating alternative indicators with communities (e.g., Reed et al. 2008). However, there may be significant ontological and epistemological differences between western science and local ways of knowing, and neither SES analyses nor participatory approaches specifically seek to reflect a culturally grounded understanding of the system and its interactions (Danielsen et al. 2009, Laird et al. 2011). As such, they may capture information that does not resonate with placebased communities, may work with incomplete data sets that are missing items of local importance, or may not accurately speak to the state and trends for broad-scale concepts, including social and ecological well-being (Sterling et al. 2017b).

Well-being indicators that are developed using a biocultural approach are likely to capture social dimensions explicitly (e.g., harvest schedule for culturally significant species) and provide a historical view of the land or seascape. Moreover, they are likely to deal with perceptions of environmental change (Bennett 2016) and can facilitate the measurement of interactions and feedbacks between humans and their environment. In doing so, they may incorporate a wider set of information than do conventional indicators of ecosystem health (e.g., species richness) and, indeed, may more accurately define environmental health according to place-based observations (Caillon et al. 2017, Sterling et al. 2017b).

\section{Context: Solomon Islands and Western Province}

Solomon Islands is a chain of nearly a thousand islands spanning $1500 \mathrm{~km}$ of the tropical western Pacific. The islands are geologically diverse and host exceptional patterns of biodiversity and endemism (Aalbersberg et al. 2012) as well as high levels of cultural and linguistic diversity (Lynch et al. 2002). Solomon Islands provides an instructive case study of the difficulty in aligning global frameworks for sustainable development to local 
Table 1. Social and ecological characteristics of the four sites, Western Province, Solomon Islands.

\begin{tabular}{lcccc}
\hline \hline Characteristic & Site A & Site B & Site C & Site D \\
\hline Island type & Raised coral & High volcanic & High volcanic & High volcanic \\
Resident adult population (July 2016) & 90 & 110 & 102 & 77 \\
Major religious denomination(s) & United Methodist, & Seventh-Day Adventist, & United Methodist & Seventh-Day Adventist \\
& Catholic, Christian & Ba'hai & & \\
Boat travel to market town & $<1 \mathrm{~h}$ & $<1 \mathrm{~h}$ & $2 \mathrm{~h}$ & $2 \mathrm{~h}$ \\
Coastal setting & Sheltered lagoon & Sheltered inlet & Open sea & Open sea \\
Access to telecommunications & Mobile and data & Mobile and data & No signal & No signal \\
\hline
\end{tabular}

well-being (Foale 2001). It is characterized by the United Nations as a "Least Developed Country," with high dependency on external aid and a small monetary economy. At the same time, however, communities in Solomon Islands have a rich and creative history of resilience to environmental pressures, as well as practices and epistemologies that continue to guide local stewardship of resources (e.g., Lauer et al. 2013).

Across Solomon Islands, access rights over land and nearshore reefs remain largely in control of local users. Approximately $90 \%$ of rural land and virtually all nearshore marine systems are controlled communally by groups that live in areas recognized as their customary home and resource base (Hviding 1998). Within these customary groups, leaders allocate use rights to community members for shifting cultivation, hunting, and coconut plantations or other cash crops (Aswani 2002). Management practices are culturally embedded in customary land- and seatenure institutions and reflect shifting demographic and ecological characteristics of different sites (Bayliss-Smith et al. 2003).

The population of Solomon Islands was > 605,000 in 2013 (Solomon Islands National Statistics Office 2015). More than $80 \%$ of the labor force is engaged in small-scale agriculture and fishing for consumption or trade. Unregulated large-scale logging has escalated since the 2000s, with significant ecological and sociological effects (Katovai et al. 2015). Extractive industries, especially timber and fishing, are significant exports, and there is increasing interest from the mining sector (Baines 2015).

\section{Sites}

This work was conducted at four sites in Western Province of Solomon Islands (Fig. 1, Table 1). The sites are all part of a national network of communities conducting conservation work in various forms (from full ridge to reef closures to smaller, temporal marine managed areas), which is facilitated by the Solomon Islands Community Conservation Partnership (SICCP). Although the pathway to implementation differed, work in each site was founded on longstanding personal and professional relationships, as well as requests from leaders at the sites for assistance to support existing conservation planning. Basing site selection in personal relationships has strengths (e.g., knowledge of cultural context) and weaknesses (e.g., expectations that are shaped by previous engagements). Regardless, it does increase the chances that the findings of the work will be able to fit into applied management planning and other activities at the sites.
Fig. 1. Solomon Islands (main map) and Western Province (inset) showing study sites A-D.

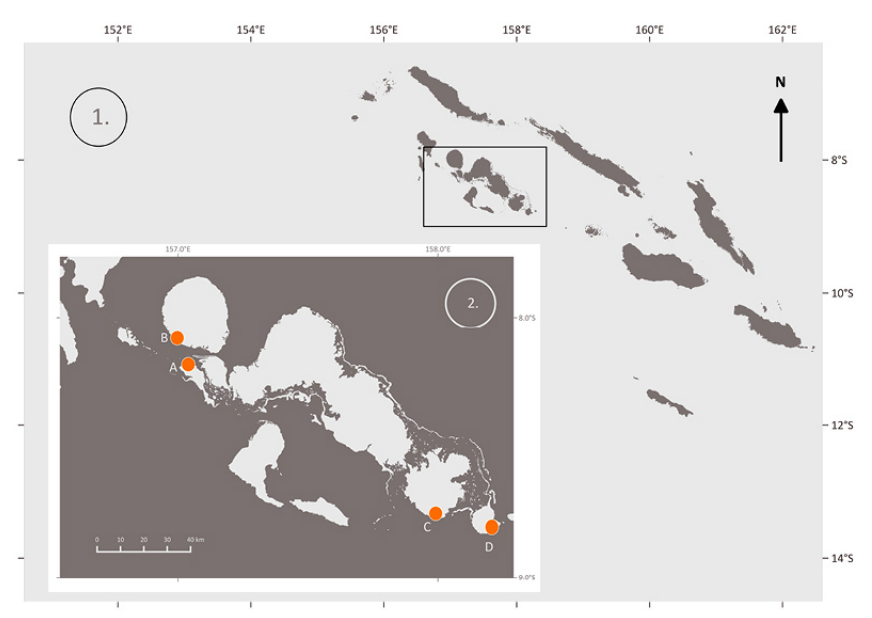

The sites represent a range of market access and ecological transformation (Table 1). They have varying degrees of connectivity to outside markets and social networks, distinct languages, and different income generating opportunities, which typically include the sale of agricultural goods, fish, and handicrafts. The sites also differ in terms of governance structure and religious affiliation, which are major determinants of daily life in Solomon Islands. In particular, the churches influence resource use, both through edict (e.g., Seventh Day Adventist churches in Solomon Islands do not typically permit consumption of shellfish) and because they are major providers of governance and leadership.

All four sites are modified human landscapes: as elsewhere in Solomon Islands, people have maintained a productive relationship with the land over generations, which has increased diversity within some habitat types and altered the distribution of some key species (Bayliss-Smith et al. 2003, Furusawa et al. 2014). At sites A and B, recent commercial logging activity has introduced roads and transformed forest systems, resulting in significant landscape-level impacts that are affecting gardening and food production. Sites C and D have not yet been modified by industrial logging, and to some extent, residents maintain systems of resource stewardship that are based on customary 
resource management practice. At sites $\mathrm{C}$ and $\mathrm{D}$, there is significant interest in commercial logging from some residents and nonresidents.

\section{Implementing the biocultural approach}

We implemented the program in five overlapping steps (Fig. 2).

Fig. 2. The five major steps of the biocultural approach used in this study. The steps were staged to begin at different times and proceeded iteratively.

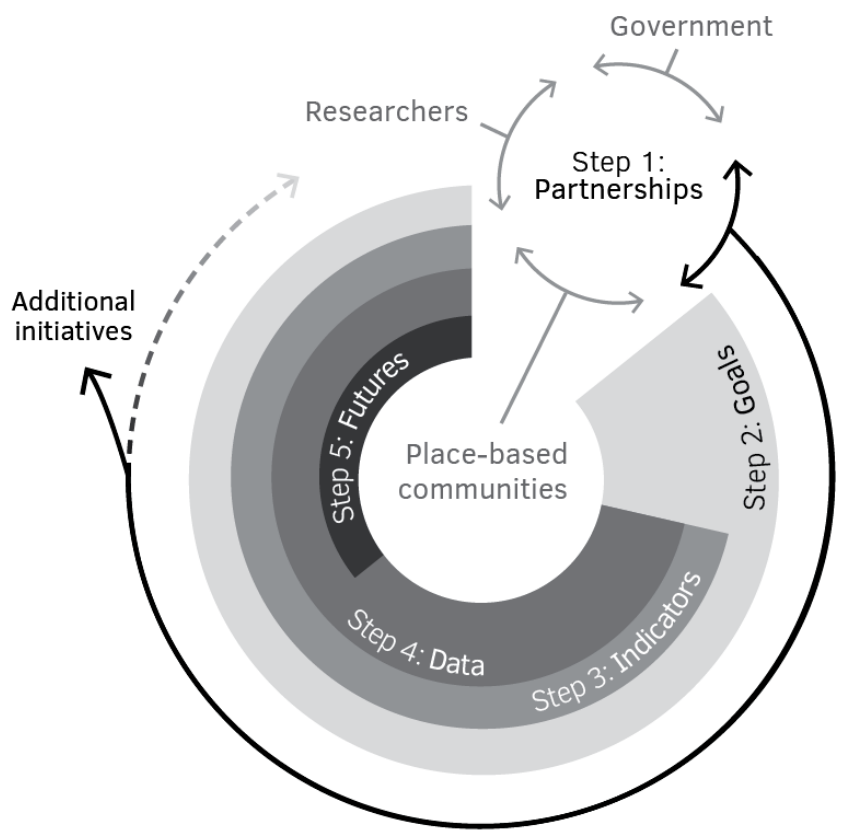

Step 1: Build partnerships and collaborations among communities, researchers, and government

The formal initiation of the program took place at the sites in 2015, with a set of workshop-style discussions around the approach, outcomes, and implications. The aim of this stage was to discuss the shape of the collaboration and mutual benefits and benefit sharing, cement personal relationships between site residents and the international team, and open communication channels for conflict resolution. At this stage, we worked with leaders at each site to identify a range of place-based researchers, some of who are coauthors of this paper. Simultaneously, the team worked to strengthen links with provincial and national governments by following the formal research permitting process and seeking regular meetings to discuss program development.

\section{Step 2: Identify goals and values}

We worked with participants at the sites to define the scope of the program using a suite of three workshops and structured discussions. The international team, with assistance from placebased researchers, led this stage during 2015, drawing lessons from elsewhere in Solomon Islands (van der Ploeg et al. 2016, Apgar et al. 2017). Participation was open and was solicited through public notices at least one week in advance of the meeting. In the first workshop, we invited participants to discuss the current state of their land, sea, and resources in a series of focus groups. In the second workshop, we held visioning exercises to begin to characterize the desired biocultural state. These exercises began by asking participants to envision their community, land, and sea in an ideal future and worked backward from there to identify common components of well-being. Drawings produced during this exercise formed a prompt for group discussions and revealed themes that would likely have not have been uncovered by written responses (e.g., the importance of maintaining cultural markers on the landscape or the need to maintain mother-daughter knowledge transmission in the garden). In the third workshop, we used large-format printed aerial photos and satellite imagery at defined time steps (spanning 1947 to 2016) as visual bases for discussions of landscape change over time. Participants drew and annotated on acetate overlays on top of the printed bases. These workshops identified key nodes and drivers of change at each site and allowed iterative discussions of the interaction between pressures on the landscape and well-being.

The workshops revealed a set of thematic elements of well-being, which were both common and variable across the sites. Healthy terrestrial and marine environments were central to most participants' vision of an ideal future, as were the presence of some form of income generation and the maintenance of food security. At all sites, participants emphasized the need to maintain cooperation, unity, and trust within the community, ideals that are widely perceived to have been declining in recent years. There were also common concerns about diet and the shifts in garden productivity, including changes in preference toward storebought and imported foods and associated health issues.

Other themes varied among the sites. For example, sites A and B both emphasized the need for income generation and development of infrastructure, particularly roads and wharves, to facilitate trade. Participants at these two sites also emphasized the need for increased access to roofing iron for completing "permanent" houses. Site C was more focused on the importance of a strong and central church and school in the community than the other sites. Participants at site D emphasized that it was critical to maintain cultural values, both as a source of income (cultural integrity was perceived to be fundamental to success as a handicrafts marketplace) and as a foundation for maintaining an "ethic of the place." Respondents at sites C and D noted that it was critical for education systems to be rooted in the local context, ideally furthering the transmission of values and cultural practices.

Step 3: Develop indicators to measure components of well-being We combined the results from the workshops, as well as subsequent discussions, to derive 16 themes that were important in the ideal futures at each site. We crafted these as outcomes statements to relate them directly to locally identified actions (Table 2). The outcome statements are not mutually exclusive.

We used the 16 themes to develop an initial draft set of indicators. Although the themes were common across the sites, the emphasis of the indicators differed. For example, within the theme of garden health, site $\mathrm{C}$ emphasized the perpetuation of indigenous varieties of taro, whereas the other three sites emphasized other crop species and the importance of wider patterns of agrobiodiversity. Indicators were discussed with participants in a series of small group meetings and were refined iteratively over two to three rounds of feedback. We then compared the draft indicator 
Table 2. Desired outcomes and components of well-being at the four sites, Western Province, Solomon Islands. Outcomes 1-16 were developed from visioning workshops at the sites; outcomes 17 and 18 were added after consulting the literature.

\begin{tabular}{llll}
\hline \hline $\begin{array}{l}\text { Nu- } \\
\text { mber }\end{array}$ & Outcome & Context & Exemplar citation \\
\hline 1 & $\begin{array}{l}\text { Reef, mangroves, and shellfish } \\
\text { beds are healthy }\end{array}$ & $\begin{array}{l}\text { The health of inshore marine resources is paramount for both foodways and livelihoods at } \\
\text { all sites. All four sites rely on nearshore reefs, and two have significant mangrove areas. Two }\end{array}$ & $\begin{array}{l}\text { McClanahan et al. } \\
\text { (2012) }\end{array}$
\end{tabular}
sites do not eat shellfish as part of the Seventh-Day Adventist church

2 Gardens are accessible and Participants highlighted the importance of gardens in maintaining appropriate food at all sites. In recent years, gardens have become less central in food production, which productive participants viewed as a negative trend. This trend was viewed as being primarily driven by changes in knowledge transmission, taste preferences, and garden pests

3 Appropriate gardening practice Workshop participants expressed concerns that current social and technical practice for is known and used agriculture is inadequate for food production. This encompasses technical knowledge (e.g., how to maintain soil health), ability to learn gardening techniques, and percieved appropriate spiritual practice

4 Diets are diverse and nutritious Diets at the four sites were perceived to have shifted toward having a greater prevalence of imported, store-bought food over garden-grown produce. Participants perceived subsequent negative issues around health and loss of cultural knowledge around food

5 Locally important agro- $\quad$ Place-based agro-biodiversity is important for the maintenance of cultural values and biodiversity is present and used resilience but has waned in recent years

6 Forest and terrestrial environment is healthy All four sites have significant terrestrial areas, which provide a variety of forest products and provisioning services. Primary and secondary forest zones are sometimes contested as potential arenas for commercial logging. Access to clean freshwater is an issue at all sites

7 Resource base is adequate for community needs The size and health of the resource base as a whole is a critical component of adaptive capacity. Community needs, in this context, are defined by participants at the sites but are considered at a systems level

8 Important local knowledge is used, transmitted, and maintained

Like many Pacific Island communities, components of local knowledge and practice remain critical to everyday life. There are concerns about knowledge transmission along with concurrent social and environmental change

Vernacular language is a key component of local identity and linkages between land and sea. Increases in migration, both in and out of the sites, along with other factors place pressure on vernacular languages. Workshop participants were also concerned about the efficacy of transmission to children transmitted and used

10 Residents cooperate and are unified around key issues

The ability to work together to solve problems was discussed during all participant workshops, both as a critical node of recent change and as a precondition for action on social and environmental issues

Closely linked with outcome 10, challenges around legitimacy of leadership and governance Jupiter and Egli (2011) define resource use management in Solomon Islands

11 Leadership is effective and transparent

Health and wealth at the sites was critical. Health, wealth, and happiness are fluidly defined and are understood as a range of objective (e.g., site-level prevalence of noncommunicable diseases) and subjective (e.g., self-rated happiness) measures

wealthy, and happy

13 Resource management bodies are legitimate and functional

14 Income-generating activities are present, shared, and viable

15 Sites have appropriate social infrastructure

Closely linked with outcome 11 , but referring specifically to communal decision-making arenas, which typically face issues in terms of leadership transparency and function Income generation is a critical concern at the sites in light of school fees, tithes, and other needs

The ability for residents to take opportunities can be enhanced or constrained by the

Reenberg et al. (2008)

y

Fazey et al. (2011)

Andersen et al. (2013)

Fazey et al. (2011)

Katovai et al. (2015)

Walter and Hamilton

(2014)

Lauer and Aswani

(2009)

Lynch et al. (2002)

presence of key infrastructure (e.g., roads, water tanks, mobile towers)

National-level processes influence communities in a number of ways, one of the most visible Kabutaulaka 2000

16 Community can deal with pressure from logging companies or other external of which is extractive logging

Malvatumauri National Council of Chiefs (2012) Jupiter and Egli (2011) market forces

17 Governance is congruent with The ability of residents at the sites to manage resources adaptively will be constrained in resource base

18 Knowledge of system limits is scenarios in which they depend on resources outside their direct control present and transmitted

Knowledge of system limits is a critical component of effective management

Fazey et al. (2011)

Foale (2006)

set with similar international programs to identify potential gaps and synergies. This resulted in the addition of a further two sets of indicator categories, which had been established as critical to building an understanding of the system but had not been identified in step 2 (see Foale 2006, Fazey et al. 2011; Table 2).

We do not display specific well-being indicators here. This is primarily because indicator development is an iterative process; the indicators will continue to be defined over the next one to two years. While the steps we took to form partnerships and promote dialogue with communities have generally been productive, biases in selection are difficult to avoid. In particular, we note the potential for the selection process to favor easily verifiable knowledge, as well as the general tendency for collaborative projects to "particularize" indigenous and local knowledge (see Agrawal 2002). To avoid these tendencies, we view our current indicator list as a draft for discussion with participants at the sites, as well as the basis for steps 4 and 5 that followed. We provide three worked examples from one site in Table 3. 
Table 3. Example of indicator development in three thematic areas at site A, Western Province, Solomon Islands.

\begin{tabular}{|c|c|c|c|}
\hline \multirow[b]{2}{*}{ Development step } & \multicolumn{3}{|c|}{ Thematic area } \\
\hline & $\begin{array}{l}\text { Appropriate gardening practice is known } \\
\text { and used }\end{array}$ & Diets are diverse and nutritious & $\begin{array}{l}\text { Reef, mangroves, and shellfish beds are } \\
\text { healthy }\end{array}$ \\
\hline 1: Build partnership & As described in text & As described in text & As described in text \\
\hline $\begin{array}{l}\text { 2: Identify goals and } \\
\text { values }\end{array}$ & $\begin{array}{l}\text { Visual outputs from visioning and current } \\
\text { state discussions indicate that, in the } \\
\text { context of rapidly changing agricultural } \\
\text { practices, mother-daughter transmission } \\
\text { of knowledge had been interrupted and } \\
\text { people do not follow best practices }\end{array}$ & $\begin{array}{l}\text { Discussions and current state workshops } \\
\text { highlight changing diets and perceived } \\
\text { links to cultural change and increased } \\
\text { rates of illness, in particular diabetes }\end{array}$ & $\begin{array}{l}\text { Visioning outputs and discussions } \\
\text { highlight the centrality of marine health } \\
\text { for livelihoods and well-being }\end{array}$ \\
\hline $\begin{array}{l}\text { 3: Identify indicators } \\
\text { to measure success }\end{array}$ & $\begin{array}{l}\text { Suggested indicators of a healthy garden } \\
\text { include robust systems of knowledge } \\
\text { transmission as well as specific practices } \\
\text { around soil and pest management }\end{array}$ & $\begin{array}{l}\text { Suggested metrics include Minimum } \\
\text { Dietary Diversity for Women, an } \\
\text { internationally used indicator for } \\
\text { community-level nutritional adequacy. } \\
\text { After discussion, participants stress it is } \\
\text { important to consider explicitly the level } \\
\text { of consumption of key varieties of sweet } \\
\text { potato }\end{array}$ & $\begin{array}{l}\text { A range of indicators identified, including } \\
\text { ease of catch, presence and size of key } \\
\text { species, and overall habitat health. After } \\
\text { discussion, key species are refined to two } \\
\text { species of shellfish (Strombus sp., } \\
\text { Polymesoda sp.), and key habitats are } \\
\text { closely identified (fringing reef, etc.) }\end{array}$ \\
\hline $\begin{array}{l}\text { 4: Measure current } \\
\text { state }\end{array}$ & $\begin{array}{l}\text { Questions in a structured interview } \\
\text { around teaching and learning in garden } \\
\text { systems (i.e., who was the major teacher; } \\
\text { are you still learning new skills); garden } \\
\text { surveys that document practice. Data } \\
\text { show that most people still report that } \\
\text { they learn from parents, but that they do } \\
\text { not practice pest or soil management } \\
\text { techniques }\end{array}$ & $\begin{array}{l}\text { Methods include structured } 24 \text {-h dietary } \\
\text { recalls and semistructured, perceptions- } \\
\text { based interviews with household heads. } \\
\text { Data indicate generally low dietary } \\
\text { diversity, which at a community level is } \\
\text { below recommended levels for nutritional } \\
\text { intake }\end{array}$ & $\begin{array}{l}\text { Multiple measures, including perceptions- } \\
\text { based social surveys (e.g., can you obtain } \\
\text { enough of species X), dive surveys, catch } \\
\text { surveys, and timed counts. Data generally } \\
\text { indicate a robust current state, although } \\
\text { with significant areas of damaged coral } \\
\text { and moderate levels of algae cover. } \\
\text { Perceptions-based measures indicate } \\
\text { marine resources satisfy needs at the } \\
\text { moment, but that most participants are } \\
\text { not optimistic about the future }\end{array}$ \\
\hline $\begin{array}{l}\text { 5: Envision scenarios } \\
\text { and enable actions }\end{array}$ & $\begin{array}{l}\text { Data are used as the basis for actions by } \\
\text { Solomon Island nongovernmental } \\
\text { organization partners, aiming to } \\
\text { strengthen garden management practice } \\
\text { at the site }\end{array}$ & $\begin{array}{l}\text { Data are used as the basis for } \\
\text { instructional workshops with Solomon } \\
\text { Island government officials and } \\
\text { nongovernmental organization partners. } \\
\text { Working with some of the women at the } \\
\text { site, the team also produces books of } \\
\text { recipes aimed at promoting discussion of } \\
\text { dietary change and improving knowledge } \\
\text { about nutrition }\end{array}$ & $\begin{array}{l}\text { Data to directly inform marine resource } \\
\text { management planning, in partnership } \\
\text { with the Solomon Islands Community } \\
\text { Conservation Partnership and Wildlife } \\
\text { Conservation Society, between } 2017 \text { and } \\
2019\end{array}$ \\
\hline $\begin{array}{l}\text { Ongoing indicator } \\
\text { development }\end{array}$ & $\begin{array}{l}\text { Further discussion will explore knowledge } \\
\text { transmission in more detail }\end{array}$ & $\begin{array}{l}\text { Refining with participants what } \\
\text { appropriate markers of adequate dietary } \\
\text { diversity might be }\end{array}$ & $\begin{array}{l}\text { Refining interpretation and trends data } \\
\text { and indicators (e.g., what level of species } \\
\mathrm{X} \text { is considered locally abundant) }\end{array}$ \\
\hline
\end{tabular}

Step 4: Measure well-being components

Using the draft indicator list, we worked with place-based researchers to collect information on the draft indicators between 2015 and 2017. We used a mixed-methods approach to data collection and adjusted the methodologies to reflect the context and type of data required. Data collected included: catch per unit effort surveys to assess size and health of nearshore coral reef fish and invertebrates; marine surveys, using both scuba and community-based methods, to assess reef health as well as fish and shellfish abundance and diversity; remote sensing, to identify key spatial characteristics of the land and sea (e.g., total area cultivated); semistructured and structured interviews, to assess aspects of diet, governance, and linkages between land and sea; terrestrial surveys, including vegetation mapping and inventory and freshwater surveys; and agro-biodiversity and ethnobotanical surveys, to build an understanding of knowledge transmission in practice. Participant selection methods varied. In structured interviews, we purposively selected participants based on household or worked specifically with subgroupings at the sites. For ecological surveys, participants were solicited from local ranger organizations.
This step was collaborative across the place-based and international members of the team, and we sought to use methods that enabled continued monitoring if there was interest at the sites. For example, botanical surveys in 2016 were structured around training for rangers at each site, based on resources developed by the University of Queensland and SICCP (Pikacha et al. 2016).

\section{Step 5: Envision scenarios and enable actions}

We are using the data collected in step 4 to assist leaders at the sites to adapt and plan for future change, with the ultimate goal of maintaining or improving well-being. This will include the collation and presentation of information (e.g., a series of books and posters), continued discussion of the data, and the development of mental models to explore relationships between particular variables of interest to communities (e.g., between specific garden pests and garden practice). These products will be tailored to each community, although we will seek to draw comparisons where useful. The international team has produced initial drafts of products, which are being refined with the full team and participants at the sites. 


\section{All stages}

Across all stages of the program, we sought to minimize the power differential between place-based participants and the research team, a common feature of research collaborations such as this (Brockington et al. 2006). We prioritized relationships between the research team (both international and Solomon Island-based) and residents at the sites, selected sites where the international team had existing relationships, and worked through nominated contact people. We took steps to establish a regular schedule of visits and we ran regular (at least monthly) meetings, as well as establishing procedures for conflict resolution. We ensured that key team members, themselves residents at the sites, were available at the sites for continued informal interactions. The program occurred in the context of ongoing programming from the SICCP and other partner NGOs, so we aligned activities with work that is expected to continue over a longer period (at least 10 years). Similarly, we explicitly sought to codesign the research with participants at each site to ensure that all work was appropriate and useful and to minimize the research-action gap (Knight et al. 2008).

We also employed research methods that aimed to promote wide participation. In particular, we sought to use visual methods widely, including collage, drawing, visual note taking, map making, storyboarding, and photographic documentation. Such methods are particularly useful in rural settings because they are well suited to engaging a range of participants and exploring how people perceive interactions between humans and the environment (Beavers and Hodgson 2011).

Finally, all work followed strict ethical guidelines based on the International Society of Ethnobiology's Code of Ethics (International Society of Ethnobiology 2006), which includes principles of free, prior, and informed consent (FPIC). In this framing, FPIC is not a one-off granting of consent by leaders at the sites (although this was obtained) but rather a continuous and reflexive process of assessment. Consent at each of the sites was based on discussion of the short-, medium-, and long-term benefits of the project, which included assistance with planning and adaptation, relevant research work such as documentation of valued plants, and the direct financial benefits from team accommodation and meals. All assistants contributing significant time to project activities (defined here as $>3 \mathrm{~h}$ ) were compensated for their time at rates set by the SICCP.

\section{DISCUSSION}

We now discuss the opportunities and challenges of the biocultural approach to developing well-being indicators, drawing on our experience as a mixed team of international and place-based researchers. We begin by outlining community perspectives on the program, and then set the work in a wider context.

\section{Community feedback}

In August 2016, the Solomon Island-based research team convened to record the perceptions and discussions from the sites. These discussions emphasized three primary points. First, the program was perceived to have been broadly relevant to leaders and participants at the sites. The team noted that all steps had been useful to catalyze discussion and facilitate engagement with the environmental and social issues at each site, some of which are perceived to affect well-being negatively. In particular, the input of Solomon Island experts in marine and agricultural systems was appreciated and promoted discussion at each site. The work was generally placed in the context of ongoing struggles for effective governance, where, despite successful resource stewardship at some sites, there is a lack of space and time for leaders and other community members to engage in discussions about current status and trends (see Fazey et al. 2011). Moreover, the use of engaging and visual methods facilitated the participation of sections of the population who are often excluded from decision making (e.g., youth and women).

Second, the research team noted that local definitions of wellbeing differ among and within sites. These differences stemmed from the geographic, environmental, and social characteristics of each site, as well as the varying priorities that were expressed during the visioning phase of the work. The research team noted that it was important for indicator sets to capture local differences effectively (e.g., between different useful plants used at each site or locally appropriate forms of governance) because these factors affect both community priorities and the capacity of leaders to respond to challenges. However, the team observed that all four sites are currently under similar pressures (e.g., the need for cash income) and that responses to these pressures (e.g., presence of resource management planning and sustainable income generating activities) could be generalized across the sites. Importantly, the team highlighted that, despite efforts to engage widely, particularly with underrepresented groups, there is no single set of well-being indicators that resonate for everyone.

Third, the team thought that it was critical to consider the long history of external engagement in Western Province. Three of the sites have experienced significant NGO engagement over the years, which had shaped expectations that external partnerships would provide immediate material benefits and that agencies would not remain over the long term (see Foale 2001, Hviding 2003). This history influenced perceptions of the program and hampered our ability to connect with some sections of the population. The place-based researchers noted that it is critical for the relationships between the international, national, and local research team to continue over the medium to long term if there is to be any practical benefit derived from the indicator development process.

\section{Opportunities}

Building on this feedback, we suggest that biocultural approaches present a number of opportunities. For one, the process has the potential to generate a significant amount of locally important and fine-grained data. Given that this information is being collected to bolster and inform topics of interest to residents at the sites, we anticipate that some data will be used directly to support action and management. For example, data from dive and snorkel surveys (e.g., invertebrate abundance) can feed directly into existing resource management planning. The data from each site will form the basis for scenario planning discussions over the coming years and will serve as a baseline to monitor activity effectiveness.

The biocultural approach described here can strengthen local access to data, link to action and management planning, and provide space for discussion and analysis. In doing so, it has the potential to strengthen the hand of place-based communities engaging with external actors (e.g., Jupiter et al. 2017). This could 
occur in at least two ways: by allowing the space for leaders to develop an agenda that can guide their engagement with agencies seeking to work with them or extract resources from their land or by improving the ability to communicate place-based perspectives with government groups and NGOs. For example, the data collected here could help leaders to monitor lack of compliance with logging agreements and codes of practice or to engage external actors to address identified weaknesses.

In Solomon Islands and elsewhere in the Pacific, knowledge is situated in place (Lauer and Aswani 2009), and well-being is drawn from intangible characteristics of communities and their links with land and sea (e.g., the strength of social networks; Hviding 1998). Indicators that are not consonant with placebased epistemologies may not accurately capture these linkages and may misrepresent the lived and spiritual landscape (Agrawal 2002). The biocultural approach provides opportunities to recognize these connections: for example, the visual methods used during the workshop phase highlighted learning and knowledge transmission as metrics of successful garden management, thus linking biophysical measures (pest abundance, garden yield) with wider issues of attachment to place, language vitality, and schooling. In particular, participants highlighted the importance of landscape and boundary knowledge in light of recent land disputes, highlighting a close link between nuanced understanding of wellbeing and social justice outcomes (Martin et al. 2016).

This work aligns with other efforts in the region that have shown the potential for culturally informed indicators to enter national development policy and planning. In Vanuatu, for example, place-based well-being indicators (including the maintenance of land tenure, the transmission of knowledge, and participation in cultural practices; Malvatumauri National Council of Chiefs 2012, Tanguay 2015) have been folded into national development planning (e.g., Government of Vanuatu 2016). The ability of a biocultural approach to indicator development to influence policy and planning will depend on whether place-based leaders are able to demonstrate differences between their priorities and government agendas, as well as some flexibility in international reporting requirements. Given that in Melanesia, effective resource management solutions are likely to stem from the cocreation of knowledge between different knowledge sources (e.g., Aswani and Hamilton 2004), this approach represents a critical step toward effective linkages between place-based communities, governments, and external agencies.

Perhaps most importantly, the process of engaging communities in identifying markers of well-being has potential to be transformative in its own right. Communities in Solomon Islands are actively and creatively working to maintain characteristics of their SES that they feel to be important in a context of change (Lauer et al. 2013). However, within the communities, there are often limited governance structures or opportunities to allow for forward planning that would tackle complex social-ecological challenges (Fazey et al. 2011). The process of identifying these indicators creates the opportunity for communities to complement their current resource management practices with detailed discussions of status and trends.

\section{Complications}

Although biocultural approaches have potential, there are conceptual and practical difficulties with enacting this type of work. For one, the time investment required is both a necessary prerogative of success and a fundamental challenge (Reid et al. 2016). In particular, ensuring that indicators are culturally appropriate and relevant requires engagement over a period of years as well as relationships that are built on trust. This can be difficult for donors and funders to sustain, and in practice, may divert resources from urgent management needs (Jupiter 2017). Given the time and resources needed to develop indicators in this way, it is difficult for national governments to become involved, which makes it difficult to build strong vertical linkages with provincial and national institutions. Moreover, the focus on building a program around place-based needs brings challenges in terms of FPIC and consent; because the outcomes are not defined at the beginning, it can be difficult to convene transparent discussions around costs and benefits. Finally, "community" can be easily misconstrued (Agrawal and Gibson 1999): all four sites are socially diverse and reflect overlapping patterns of social interactions and obligations that vary for individuals in different contexts.

There are also issues in translating indicators between local and global settings. If we can identify ways to compare and aggregate across sites, local well-being indicators will become more relevant to national bodies, which may facilitate alignment between external and place-based actors. This, of course, is challenging: many such indicators represent, by definition, locally defined interests, and national- or global-level analyses require a mix of tailored local and generalized global indicators (Tanguay 2015). One way to proceed is to develop common thematic areas or outcome statements and allow flexibility within each for appropriate indicators or methodologies. For example, reef fish biomass (mass per area) is an indicator of reef ecosystem state that is comparable and useful to managers, even if it is measured in different ways (McClanahan et al. 2012). Ultimately, not all indicators that can support local action will be relevant at global scales; what is needed now is a framework or set of categories that can identify where trend- and perception-based measures may be able to complement and add value to national development planning (Sterling et al. 2017a,b).

Many of the difficulties of implementing a biocultural approach stem from a well-documented source: the power differential between external researchers and place-based peoples (Smith 1999). We took steps to minimize this and were able to craft a program that maintained close links to communities at the project sites, as well as a draft well-being indicator set that was drawn from the social and cultural contexts. Despite this, our success was limited in some key ways. For one, no members of the international research team who were initially granted research funding are from the project sites, meaning that they have limited place-based knowledge. Partly because of this, our ability to align research to existing agendas at the sites was limited. Moreover, decisions about programming were largely driven by the international team members, and at times, geography and logistics have limited the discussion of indicators and outputs at the sites. We hope that by using a biocultural approach, by seeking continual engagement and partnership with place-based actors, and by basing this work within existing relationships and 
networks, we (the entire research team) have been able to ground this work in a meaningful way. However, it is important to note the limits to this project model, which are likely to be a factor in all projects that involve externally based or funded project members.

\section{CONCLUSION}

In Melanesia, resource management success hinges on strong linkages with human livelihoods and well-being. Failure to build these linkages may result in monitoring and evaluation that is misaligned with place-based priorities, resulting in ineffective programming and limited long-term outcomes. We have argued that biocultural approaches to well-being indicator development may be able to inform localized responses to key issues and have the potential to guide better engagement between external NGOs and place-based communities. However, the tensions that we discuss above, between description and particularization, between input and ownership, and between the value of closely held and widely shared information, are real and require constant negotiation if they are to achieve just and sustainable outcomes (Sterling et al. 2017a).

In closing, we make three observations. The first is that there is a disconnect between lived experience at the sites and current measures of well-being at provincial and national scales. There are sizeable challenges in the measurement and monitoring of progress (Tanguay 2015), along with multiple examples of externally driven approaches that do not align with local needs and priorities. We argue that it is critical to continue to explore and bridge this disconnect because the lack of both local voices and understanding of place-based well-being seriously compromises the utility and equity of national development strategies (Bunce et al. 2010).

Further, we note that process is critical in ensuring that well-being indicators are relevant and useful at local scales. Participants considered this program useful because it created space for envisioning solutions and combining external and internal sources of knowledge, and improved the ability to interface with central or local government. In particular, even at sites that effectively govern resources, the space, time, and data to support forward planning discussions can be hard to obtain. We find that a biocultural approach can assist with this, and we will continue to work to use these indicators to support place-based well-being and link with different levels of government.

In general, we believe that biocultural approaches to well-being indicator development are able to create a conduit for respectful engagement between international groups with place-based communities, through which partnerships can emerge. The process increases the scope for place-based communities to engage outward in meaningful ways, and may be a step on the path to more equitable engagement by external entities in natural resource management and conservation.

Responses to this article can be read online at: http://www.ecologyandsociety.org/issues/responses. $\mathrm{php/9867}$

\section{Acknowledgments:}

We sincerely thank leaders and community members at the four sites for their consent and participation in this work. In particular, we thank Julie Belavaqara and Rayliss Luluta for their contributions to this work. The presented material is based on work supported by the National Science Foundation under grants EF-1427091 and 1444184. Any opinions, findings, and conclusions or recommendations expressed in this material are those of the author (s) and do not necessarily reflect the views of the National Science Foundation. This research was refined through discussion with the Assessing Biocultural Indicators Working Group supported in part by SNAPP: Science for Nature and People Partnership, a collaboration of The Nature Conservancy, the Wildlife Conservation Society, and the National Center for Ecological Analysis and Synthesis at the University of California, Santa Barbara. Generous support for this project also comes from the Gordon and Betty Moore Foundation, Lynette and Richard Jaffe, the Jaffe Family Foundation, The John D. and Catherine T. MacArthur Foundation (under grant 13-105118-000-INP), and the Tiffany \& Co. Foundation.

\section{LITERATURE CITED}

Aalbersberg, B., M. Avosa, R. James, C. Kaluwin, P. Lokani, J. Opu, S. Siwatibau, M. Tuiwawa, H. Waqa-Sakiti, and A. W. Tordoff. 2012. Ecosystem profile: East Melanesian Islands biodiversity hotspot. University of the South Pacific for the Critical Ecosystem Partnership Fund, Suva, Fiji. [online] URL: https://www.cepf.net/SiteCollectionDocuments/east_melanesian_islands/ EMI ecosystem profile.pdf

Agrawal, A. 2002. Indigenous knowledge and the politics of classification. International Social Science Journal 54 (173):287-298. http://dx.doi.org/10.1111/1468-2451.00382

Agrawal, A., and C. C. Gibson. 1999. Enchantment and disenchantment: the role of community and natural resource conservation. World Development 27(4):629-649. http://dx.doi. org/10.1016/S0305-750X(98)00161-2

Andersen, A. B., S. H. Thilsted, A. M. Schwarz. 2013. Food and nutrition security in Solomon Islands. CGIAR Research Program on Aquatic Agricultural Systems, Penang, Malaysia. [online] URL: http://pubs.iclarm.net/resource centre/WF_3544.pdf

Apgar, J. M., P. J. Cohen, B. D. Ratner, S. de Silva, M.-C. Buisson, C. Longley, R. Bastakoti, and E. Mapedza. 2017. Identifying opportunities to improve governance of aquatic agricultural systems through participatory action research. Ecology and Society 22(1):9. http://dx.doi.org/10.5751/ES-08929-220109

Armitage, D., C. Béné, A. T. Charles, D. Johnson, and E. H. Allison. 2012. The interplay of well-being and resilience in applying a social-ecological perspective. Ecology and Society 17 (4):15. http://dx.doi.org/10.5751/ES-04940-170415

Aswani, S. 2002. Assessing the effects of changing demographic and consumption patterns on sea tenure regimes in the Roviana Lagoon, Solomon Islands. Ambio 31(4):272-284. http://dx.doi. org/10.1579/0044-7447-31.4.272 
Aswani, S., and R. J. Hamilton. 2004. Integrating indigenous ecological knowledge and customary sea tenure with marine and social science for conservation of bumphead parrotfish (Bolbometopon muricatum) in the Roviana Lagoon, Solomon Islands. Environmental Conservation 31(1):69-83. http://dx.doi. org/10.1017/S037689290400116X

Baines, G. 2015. Solomon Islands is unprepared to manage a minerals-based economy. SSGM Discussion Paper 2015/6. Coral Bell School of Asia Pacific Affairs, Australian National University, Canberra, Australia. [online] URL: http://ssgm. bellschool.anu.edu.au/sites/default/files/publications/attachments/2015-12/ DP 20156 Baines 0.pdf

Bayliss-Smith, T., E. Hviding, and T. Whitmore. 2003. Rainforest composition and histories of human disturbance in Solomon Islands. Ambio 32(5):346-352. http://dx.doi.org/10.1579/0044-7$\underline{447-32.5 .346}$

Beavers, K. A., and K. Hodgson. 2011. How arts and cultural strategies enhance community engagement and participation. American Planning Association, Chicago, Illinois, USA. [online] URL: https://www.planning.org/research/arts/briefingpapers/engagement. $\underline{\mathrm{htm}}$

Bennett, N. J. 2016. Using perceptions as evidence to improve conservation and environmental management. Conservation Biology 30(3):582-592. http://dx.doi.org/10.1111/cobi.12681

Bergamini, N., R. Blasiak, P. Eyzaguirre, K. Ichikawa, D. Mijatovic, F. Nakao, and S. M. Subramamian. 2013. Indicators of resilience in socio-ecological production landscapes (SEPLS). UNU-IAS Policy Report. United Nations University Institute of Advanced Studies, Yokohama, Japan. [online] URL: https://www. bioversityinternational.org/fileadmin/user upload/online library/ publications/pdfs/Indicators of Resilience in Socioecological Production Landscapes SEPLs 1676.pdf

Biedenweg, K., H. Harguth, and K. Stiles. 2017. The science and politics of human well-being: a case study in cocreating indicators for Puget Sound restoration. Ecology and Society 22(3):11. https:// doi.org/10.5751/ES-09424-220311

Brockington, D., J. Igoe, and K. Schmidt-Soltau. 2006. Conservation, human rights, and poverty reduction. Conservation Biology 20(1):250-252. http://dx.doi.org/10.1111/j.1523-1739.2006.00335. $\underline{\mathrm{X}}$

Brondizio, E. S., E. Ostrom, and O. R. Young. 2009. Connectivity and the governance of multilevel social-ecological systems: the role of social capital. Annual Review of Environment and Resources 34:253-278. http://dx.doi.org/10.1146/annurev.environ.020708.100707

Bunce, M., K. Brown, and S. Rosendo. 2010. Policy misfits, climate change and cross-scale vulnerability in coastal Africa: how development projects undermine resilience. Environmental Science and Policy 13(6):485-497. http://dx.doi.org/10.1016/j. envsci.2010.06.003

Büscher, B., R. Fletcher, D. Brockington, C. Sandbrook, W. M. Adams, L. Campbell, C. Corson, W. Dressler, R. Duffy, N. Gray, G. Holmes, A. Kelly, E. Lunstrum, M. Ramutsindela, and K. Shanker. 2017. Half-Earth or whole Earth? Radical ideas for conservation, and their implications. Oryx 51(3):407-410. http:// dx.doi.org/10.1017/S0030605316001228
Caillon, S., G. Cullman, B. Verschuuren, and E. J. Sterling. 2017. Moving beyond the human-nature dichotomy through biocultural approaches: including ecological well-being in resilience indicators. Ecology and Society 22(4):27. https://doi. org/10.5751/ES-09746-220427

Danielsen, F., N. D. Burgess, A. Balmford, P. F. Donald, M. Funder, J. P. G. Jones, P. Alviola, D. S. Balete, T. Blomley, J. Brashares, B. Child, M. Enghoff, J. Fjeldså, S. Holt, H. Hübertz, A. E. Jensen, P. M. Jensen, J. Massao, M. M. Mendoza, Y. Ngaga, M. K. Poulsen, R. Rueda, M. Sam, T. Skielboe, G. Stuart-Hill, E. Topp-Jørgensen, and D. Yonten. 2009. Local participation in natural resource monitoring: a characterization of approaches. Conservation Biology 23(1):31-42. http://dx.doi.org/10.1111/ j.1523-1739.2008.01063.X

Diener, E. 2000. Subjective well-being: the science of happiness and a proposal for a national index. American Psychologist 55 (1):34-43. http://dx.doi.org/10.1037/0003-066X.55.1.34

Dudley, N., editor. 2008. Guidelines for applying protected area management categories. International Union for Conservation of Nature, Gland, Switzerland. [online] URL: https://www.iucn.org/ $\underline{\text { content/guidelines-applying-protected-area-management-categories-0 }}$

Escobar, C. 2014. Community well-being in Bolivia: an indigenous perspective. Pages 42-57 in B. Verschuuren, S. M. Subramanian, and W. Hemstra, editors. Community well-being in biocultural landscapes: Are we living well? Practical Action Publishing, Rugby, UK. http://dx.doi.org/10.3362/9781780448374.003

Fazey, I., N. Pettorelli, J. Kenter, D. Wagatora, and D. Schuett. 2011. Maladaptive trajectories of change in Makira, Solomon Islands. Global Environmental Change 21(4):1275-1289. http://dx. doi.org/10.1016/j.gloenvcha.2011.07.006

Foale, S. 2001. "Where's our development?" Landowner aspirations and environmentalist agendas in Western Solomon Islands. Asia Pacific Journal of Anthropology 2(2):44-65. http:// dx.doi.org/10.1080/14442210110001706105

Foale, S. 2006. Is coral reef conservation possible without science education in Melanesia? Is science education possible without development? Pages 1274-1278 in Proceedings of the 10th International Coral Reef Symposium. International Society for Reef Studies, Waco, Texas, USA.

Fraser, E. D. G., A. J. Dougill, W. E. Mabee, M. Reed, and P. McAlpine. 2006. Bottom up and top down: analysis of participatory processes for sustainability indicator identification as a pathway to community empowerment and sustainable environmental management. Journal of Environmental Management 78(2):114-127. http://dx.doi.org/10.1016/j.jenvman.2005.04.009

Furusawa, T., M. Q. Sirikolo, M. Sasaoka, and R. Ohtsuka. 2014. Interaction between forest biodiversity and people's use of forest resources in Roviana, Solomon Islands: implications for biocultural conservation under socioeconomic changes. Journal of Ethnobiology and Ethnomedicine 10:10. https://doi. org/10.1186/1746-4269-10-10

Gavin, M. C., J. McCarter, A. Mead, F. Berkes, J. R. Stepp, D. Peterson, and R. Tang. 2015. Defining biocultural approaches to conservation. Trends in Ecology and Evolution 30(3):140-145. http://dx.doi.org/10.1016/j.tree.2014.12.005 
Government of Vanuatu. 2016. Vanuatu 2030: the people's plan: national sustainable development plan 2016-2030. Government of Vanuatu, Port Vila, Vanuatu. [online] URL: https://www.cbd.int/ doc/meetings/mar/soiws-2016-05/other/soiws-2016-05-vanuatu-05en.pdf

Hughes, S., A. Yau, L. Max, N. Petrovic, F. Davenport, M. Marshall, T. R. McClanahan, E. H. Allison, and J. E. Cinner. 2012. A framework to assess national level vulnerability from the perspective of food security: the case of coral reef fisheries. Environmental Science and Policy 23:95-108. http://dx.doi. org/10.1016/j.envsci.2012.07.012

Hviding, E. 1998. Contextual flexibility: present status and future of customary marine tenure in Solomon Islands. Ocean and Coastal Management 40(2-3):253-269. http://dx.doi.org/10.1016/ $\underline{\mathrm{S} 0964-5691(98) 00042-8}$

Hviding, E. 2003. Contested rainforests, NGOs, and projects of desire in Solomon Islands. International Social Science Journal 55 (178):539-554. http://dx.doi.org/10.1111/j.0020-8701.2003.05504003. $\underline{\mathrm{X}}$

International Society of Ethnobiology. 2006. International Society of Ethnobiology code of ethics (with 2008 additions). International Society of Ethnobiology, Bristol, Vermont, USA. http://ethnobiology.net/code-of-ethics/

Jupiter, S. 2017. Culture, kastom and conservation in Melanesia: What happens when worldviews collide? Pacific Conservation Biology 23(2):139-145. https://doi.org/10.1071/PC16031

Jupiter, S. D., and D. P. Egli. 2011. Ecosystem-based management in Fiji: successes and challenges after five years of implementation. Journal of Marine Biology 2011:940765. http:// dx.doi.org/10.1155/2011/940765

Jupiter, S. D., A. Wenger, C. J. Klein, S. Albert, S. Mangubhai, J. Nelson, L. Teneva, V. J. Tulloch, A. T. White, and J. E. M. Watson. 2017. Opportunities and constraints for implementing integrated land-sea management on islands. Environmental Conservation 44 (3):254-266. http://dx.doi.org/10.1017/S0376892917000091

Kabutaulaka, T. T. 2000. Rumble in the jungle: land, culture and (un)sustainable logging in Solomon Islands. Pages 88-97 in E. Hooper, editor. Culture and sustainable development in the Pacific. Australian National University E Press, Canberra, Australia. [online] URL: https://press.anu.edu.au/publications/culture-and$\underline{\text { sustainable-development-pacific }}$

Katovai, E., W. Edwards, and W. F. Laurance. 2015. Dynamics of logging in Solomon Islands: the need for restoration and conservation alternatives. Tropical Conservation Science 8 (3):718-731. http://dx.doi.org/10.1177/194008291500800309

Knight, A. T., R. M. Cowling, M. Rouget, A. Balmford, A. T. Lombard, and B. M. Campbell. 2008. Knowing but not doing: selecting priority conservation areas and the researchimplementation gap. Conservation Biology 22(3):610-617. http:// dx.doi.org/10.1111/j.1523-1739.2008.00914.X

Laird, S. A., G. L. Awung, R. J. Lysinge, and L. E. Ndive. 2011. The interweave of people and place: biocultural diversity in migrant and indigenous livelihoods around Mount Cameroon. International Forestry Review 13(3):275-293. https://doi. org/10.1505/146554811798293890
Lauer, M., S. Albert, S. Aswani, B. S. Halpern, L. Campanella, and D. La Rose. 2013. Globalization, Pacific Islands, and the paradox of resilience. Global Environmental Change 23(1):40-50. http://dx.doi.org/10.1016/j.gloenvcha.2012.10.011

Lauer, M., and S. Aswani. 2009. Indigenous ecological knowledge as situated practices: understanding fishers' knowledge in the Western Solomon Islands. American Anthropologist 111 (3):317-329. http://dx.doi.org/10.1111/j.1548-1433.2009.01135.x

Lynch, J., M. Ross, and T. Crowley. 2002. The Oceanic Languages. Curzon Press, Richmond, UK.

Maffi, L. 2005. Linguistic, cultural, and biological diversity. Annual Review of Anthropology 34:599-617. http://dx.doi. org/10.1146/annurev.anthro.34.081804.120437

Malvatumauri National Council of Chiefs. 2012. Alternative indicators of well-being for Melanesia: Vanuatu pilot study report. Malvatumauri National Council of Cheifs, Port Vila, Vanuatu. [online] URL: http://www.christensenfund.org/wp-content/ uploads/2012/11/Alternative-Indicators-Vanuatu.pdf

Martin, A., B. Coolsaet, E. Corbera, N. M. Dawson, J. A. Fraser, I. Lehmann, and I. Rodriguez. 2016. Justice and conservation: the need to incorporate recognition. Biological Conservation 197:254-261. http://dx.doi.org/10.1016/j.biocon.2016.03.021

McClanahan, T. R., S. D. Donner, J. A. Maynard, M. A. MacNeil, N. A. J. Graham, J. Maina, A. C. Baker, J. B. Alemu I., M. Beger, S. J. Campbell, E. S. Darling, C. M. Eakin, S. F. Heron, S. D. Jupiter, C. J. Lundquist, E. McLeod, P. J. Mumby, M. J. Paddack, E. R. Selig, and R. van Woesik. 2012. Prioritizing key resilience indicators to support coral reef management in a changing climate. Plos One 7(8):e42884. http://dx.doi.org/10.1371/journal. pone. 0042884

Naeem, S., R. Chazdon, J. E. Duffy, C. Prager, and B. Worm. 2016. Biodiversity and human well-being: an essential link for sustainable development. Proceedings of the Royal Society B 283 (1844):20162091. http://dx.doi.org/10.1098/rspb.2016.2091

Pikacha, P., T. Lavery, M. Sirikolo, D. Boseto, D. Pikacha Jr., and E. Pollard. 2016. Solomon Islands ranger skills guide. University of Queensland, Brisbane, Australia.

Reed, M. S., A. J. Dougill, and T. R. Baker. 2008. Participatory indicator development: What can ecologists and local communities learn from each other? Ecological Applications 18 (5):1253-1269. http://dx.doi:10.1890/07-0519.1

Reenberg, A., T. Birch-Thomsen, O. Mertz, B. Fog, and S. Christiansen. 2008. Adaptation of human coping strategies in a small island society in the SW Pacific - 50 years of change in the coupled human-environment system on Bellona, Solomon Islands. Human Ecology 36(6):807-819. https://doi.org/10.1007/ s10745-008-9199-9

Reid, R. S., D. Nkedianye, M. Y. Said, D. Kaelo, M. Neselle, O. Makui, L. Onetu, S. Kiruswa, N. O. Kamuaro, P. Kristjanson, J. Ogutu, S. B. BurnSilver, M. J. Goldman, R. B. Boone, K. A. Galvin, N. M. Dickson, and W. C. Clark. 2016. Evolution of models to support community and policy action with science: balancing pastoral livelihoods and wildlife conservation in savannas of East Africa. Proceedings of the National Academy of Sciences 113(17):4579-4584. http://dx.doi.org/10.1073/pnas.0900313106 
Smith, L. T. 1999. Decolonising methodologies: research and indigenous peoples. Zed Books, London, UK.

Solomon Islands National Statistics Office. 2015. Solomon Islands 2012/13 household income and expenditure survey: provincial analytical report. Solomon Islands National Statistics Office, Honiara, Solomon Islands. [online] URL: http://www.mof.gov.

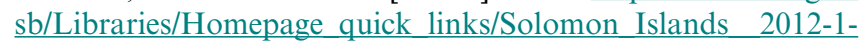
3 Household Income and Expenditure Survey HIES PROVINCIAL -ANALYSIS - REPORT.sflb.ashx

Sterling, E. J., C. Filardi, A. Toomey, A. Sigouin, E. Betley, N. Gazit, J. Newell, S. Albert, D. Alvira, N. Bergamini, M. Blair, D. Boseto, K. Burrows, N. Bynum, S. Caillon, J. E. Caselle, J. Claudet, G. Cullman, R. Dacks, P. B. Eyzaguirre, S. Gray, J. Herrera, P. Kenilorea, K. Kinney, N. Kurashima, S. Macey, C. Malone, S. Mauli, J. McCarter, H. McMillen, P. Pascua, P. Pikacha, A. L. Porzecanski, P. de Robert, M. Salpeteur, M. Sirikolo, M. H. Stege, K. Stege, T. Ticktin, R. Vave, A. Wali, P. West, K. B. Winter, and S. D. Jupiter. 2017a. Biocultural approaches to well-being and sustainability indicators across scales. Nature Ecology and Evolution 1:1798-1806. http://dx.doi.org/10.1038/s41559-017-0349-6

Sterling, E., T. Ticktin, T. K. K. Morgan, G. Cullman, D. Alvira, P. Andrade, N. Bergamini, E. Betley, K. Burrows, S. Caillon, J. Claudet, R. Dacks, P. Eyzaguirre, C. Filardi, N. Gazit, C. Giardina, S. Jupiter, K. Kinney, J. McCarter, M. Mejia, K. Morishige, J. Newell, L. Noori, J. Parks, P. Pascua, A. Ravikumar, J. Tanguay, A. Sigouin, T. Stege, M. Stege, and A. Wali. $2017 b$. Culturally grounded indicators of resilience in social-ecological systems. Environment and Society 8:63-95. http://dx.doi. org/10.3167/ares.2017.080104

Tanguay, J. 2015. Alternative indicators of wellbeing for Melanesia: cultural values driving public policy. Pages 162-172 in L. MacDowall, M. Badham, E. Blomkamp, and K. Dunphy, editors. Making culture count: the politics of culturalmeasurement. Palgrave Macmillan, London, UK.

Taylor, J. 2008. Indigenous peoples and indicators of well-being: Australian perspectives on United Nations global frameworks. Social Indicators Research 87(1):111-126. http://dx.doi. org/10.1007/s11205-007-9161-Z

Tengö, M., E. S. Brondizio, T. Elmqvist, P. Malmer, and M. Spierenburg. 2014. Connecting diverse knowledge systems for enhanced ecosystem governance: the multiple evidence base approach. Ambio 43(5):579-591. http://dx.doi.org/10.1007/ s13280-014-0501-3

van der Ploeg, J., J. Albert, M. Apgar, G. Bennett, D. Boso, P. Cohen, C. Daokalia, J. Faiau, D. Haohau, E. Iramu, G. Orirana, M. Rice, E. Saeni, F. Siota, M. Sukulu, R. Sulu, B. Suruma, H. Teioli, P. Tikai, and A.-M. Schwarz. 2016. Learning from the lagoon: research in development in Solomon Islands. CGIAR Research Program on Aquatic Agricultural Systems, Penang, Malaysia.

van Oudenhoven, F. J. W., D. Mijatovic, and P. B. Eyzaguirre. 2011. Social-ecological indicators of resilience in agrarian and natural landscapes. Management of Environmental Quality 22 (2):154-173. http://dx.doi.org/10.1108/14777831111113356
Walter, R. K., and R. J. Hamilton. 2014. A cultural landscape approach to community-based conservation in Solomon Islands. Ecology and Society 19(4):41. http://dx.doi.org/10.5751/ ES-06646-190441

Westoby, P. 2010. "We have plenty": re-thinking custom and community economic development within Vanuatu. Journal of Development Support 2:20-38.

Wilkie, D., M. Wieland, and D. Detoeuf. 2015. A guide to the modified Basic Necessities Survey: Why and how to conduct BNS in conservation landscapes. Wildlife Conservation Society, New York, New York, USA. [online] URL: http://programs.wcs.org/ DesktopModules/Bring2mind/DMX/Download.aspx?

EntryId=28643\&PortalId=97\&DownloadMethod=attachment 